\title{
Measurement of Sn and In Solidification Undercooling and Lattice Expansion Using In Situ X-Ray Diffraction
}

\author{
JOHN W. ELMER ${ }^{1,3}$ and ELIOT D. SPECHT ${ }^{2}$ \\ 1.-Lawrence Livermore National Laboratory, Livermore, CA 94550, USA. 2.-Oak Ridge \\ National Laboratory, Oak Ridge, TN 37831, USA. 3.—e-mail: elmer1@llnl.gov
}

The solidification behavior of two low-melting-point metals, Sn and In, on three substrates has been examined using in situ x-ray diffraction. Undercoolings of up to $56.1^{\circ} \mathrm{C}$ were observed for Sn solidified on graphite, which is a nonwetting substrate, while lower undercoolings were observed for $\mathrm{Sn}$ on $\mathrm{Au} /$ $\mathrm{Ni} / \mathrm{Cu}\left(17.3^{\circ} \mathrm{C}\right)$ and on $\mathrm{Cu}\left(10.5^{\circ} \mathrm{C}\right)$. Indium behaved quite differently, showing undercoolings of less than $4^{\circ} \mathrm{C}$ on all three substrates. The lattice expansion/ contraction behavior of Sn, In, and intermetallic compounds (IMCs) that formed during the reaction of $\mathrm{Sn}$ with $\mathrm{Au} / \mathrm{Ni} / \mathrm{Cu}$ surfaces were also measured during heating and cooling. Results showed anisotropic and nonlinear expansion of both Sn and In, with a contraction, rather than expansion, of the basal planes of In during heating. The principal IMC that formed between Sn and the $\mathrm{Au} / \mathrm{Ni} / \mathrm{Cu}$ surface was characterized as $\mathrm{Cu}_{6} \mathrm{Sn}_{5}$, having an average expansion coefficient of $13.6 \times 10^{-6} /{ }^{\circ} \mathrm{C}$, which is less than that of $\mathrm{Sn}$ or $\mathrm{Cu}$.

Key words: In situ x-ray diffraction, solidification, nucleation, undercooling, $\mathrm{Sn}$, In, lead-free solders, wetting, nonlinear expansion, intermetallic compounds, synchrotron radiation

\section{INTRODUCTION}

Undercooling of solder alloys prior to solidification can produce large grains and nonequilibrium microstructures, which have undesirable mechanical properties. ${ }^{1,2}$ Many Sn-based lead-free solder alloys display these problems due to large undercooling that results from the difficult nucleation of the $\beta$-Sn phase. ${ }^{2}$ In pure $\mathrm{Sn}$, undercoolings of over $100^{\circ} \mathrm{C}$ below its melting temperature have been observed under carefully controlled conditions, ${ }^{2,3}$ which represents one of the highest amounts of undercooling relative to melting temperature of any elemental metal. ${ }^{3}$ Undercooling in Sn was shown to increase monotonically with decreasing solder ball size,${ }^{4}$ and even under normal processing conditions at moderately low cooling rates, undercoolings of up to $40^{\circ} \mathrm{C}$ have been observed. ${ }^{2,4,5}$ The undercooling results in very fast-growing $\beta$-Sn dendrites, and produces a textured microstructure with few individual grains in the solder joint. ${ }^{2,6-8}$ This unusual

(Received June 12, 2010; accepted November 10, 2010; published online December 15, 2010) solidification behavior has also been observed in Snrich solder alloys, which display undercoolings of $25^{\circ} \mathrm{C}$ to $40^{\circ} \mathrm{C},{ }^{2,4,5}$ resulting again in very fastgrowing $\beta$-Sn dendrites that create a textured microstructure with few individual dendrites in the solder joint. The microstructures that form under these conditions produce anisotropic tetragonal $\beta$ Sn grains that are not randomized, leading to mechanical weakness of the joint, particularly where thermal fatigue is a concern ${ }^{9-13}$ due to the anisotropic behavior in lattice expansion.

Enhancing nucleation through microalloying and careful control of solder composition are under consideration as practical methods to reduce undercooling of lead-free solders, ${ }^{14}$ however the mechanisms for the difficult nucleation of $\beta$-Sn are not well understood. Difficult nucleation may be due to its body-centered tetragonal (bct) crystal structure, and/or its stable native oxide may contribute as potential nucleation barriers that increase undercooling. ${ }^{2}$ Although Sn-based alloys represent the vast majority of lead-free solders, In and In-based alloys represent a sizeable number of alternative lead-free solders due to their lower melting points 
and oftentimes more ductile behavior than Sn-based lead-free solders. Both Sn and In have tetragonal structures above room temperature, ${ }^{15}$ yet undercooling of In-based solders does not appear to be a significant concern. This may be related to the fact that, even though both elements have tetragonal crystal structures, their crystal structures are quite distinct. The bct structure of Sn is compressed along the $c$-axis, having a $c / a$ ratio of 0.5456 , while the simple tetragonal structure of In is elongated along the $c$-axis, having a $c / a$ ratio of $1.525 .^{16}$

The observed undercooling of Sn and In, and their alloys, also depends strongly on the substrate. The substrate can react with the solder and be wetted to varying degrees depending on its composition. Substrates that are wetted well by the solder will cause the solder to spread out, creating higher surface area-to-volume ratios, and enhance nucleation of the solid phase, thereby reducing undercooling. In addition, chemical reactions between the substrate and solder can form compounds that may assist with nucleation of the bulk solder. Substrates that do not react with the solder, such as graphite, are not wetted by the solder and favor higher undercoolings. New experimental methods such as in situ x-ray diffraction are beginning to be used to help understand microstructural and intermetallic compound (IMC) formation in solder alloys and solder joints. ${ }^{17,18}$ This paper continues along these lines, using in situ x-ray diffraction to study Sn and In melted and solidified on different substrates to directly observe the amount of undercooling prior to solidification. In addition, anisotropic lattice expansion of the tetragonal crystal structures of In and Sn was measured during heating and cooling, as well as lattice expansion for IMCs that formed between $\mathrm{Sn}$ and the $\mathrm{Au} / \mathrm{Ni} / \mathrm{Cu}$ substrate.

\section{EXPERIMENTAL PROCEDURES}

In situ, real-time, $\mathrm{x}$-ray diffraction measurements were conducted on thin foils of Sn and In during rapid heating and cooling of samples under controlled conditions. These experiments were performed at the Advanced Photon Source (APS), using the UNICAT beam line BM-33-C with x-ray beam energies of either $29.1 \mathrm{keV}$ or $27.8 \mathrm{keV}$ from a ring current of $100 \mathrm{~mA}$. These energies are just below the Sn K absorption edge of $29.2 \mathrm{keV}$ and the In $\mathrm{K}$ absorption edge of $27.9 \mathrm{keV}$, respectively. The calculated penetration depths for these energies are approximately $9.6 \mu \mathrm{m}$ in Sn and $7.4 \mu \mathrm{m}$ in In for a $5^{\circ}$ angle of incidence based on mass absorption coefficients of $45.42 / \mathrm{cm}$ for $\mathrm{Sn}$, and $59.27 / \mathrm{cm}$ for In. ${ }^{19}$

The x-ray beam line was set up with a watercooled $\mathrm{Si}(111)$ monochromator, and the beam was focused and sized to dimensions of $\sim 2 \mathrm{~mm}$ wide by $0.5 \mathrm{~mm}$ high using a dynamically bent Si crystal and collimator slits. A schematic illustration of the experimental setup is shown in Fig. 1, where the incoming focused monochromatic beam is shaped

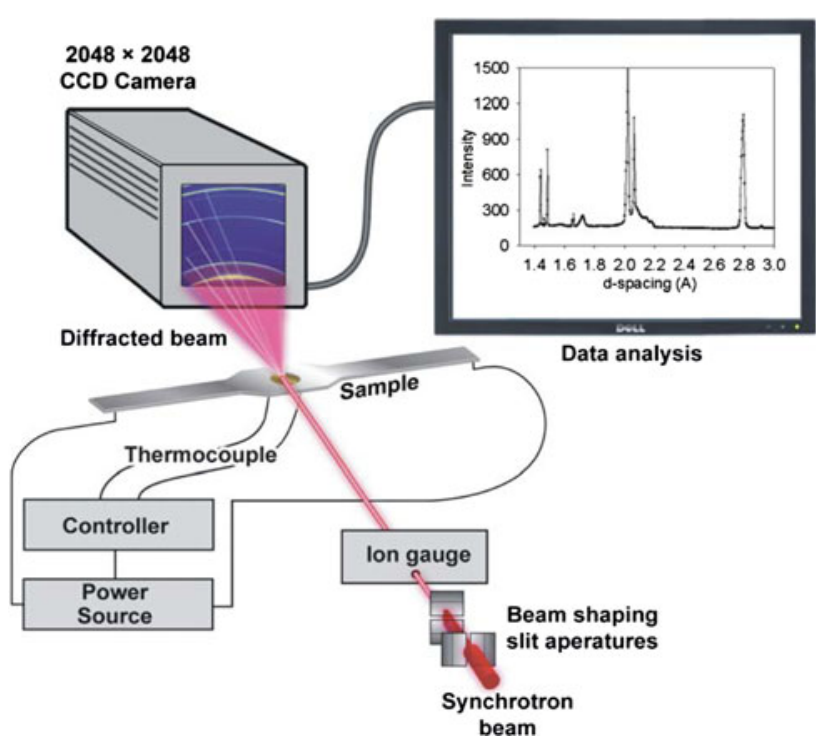

Fig. 1. Schematic of the synchrotron setup showing the basic elements for direct observations of materials being resistively heated. The sample is enclosed in an environmental chamber (not shown) to protect it from oxidation.

with horizontal and vertical slits, and the beam's flux is measured with an ion chamber before the $\mathrm{x}$-rays strike the sample. The diffracted beams are detected with a $2048 \times 2048$ pixel areal detector placed downstream from the sample. This detector is similar to one used in previous experiments, and additional details can be found elsewhere for measurements of phase transformations and stress relaxation in metals, ${ }^{20-22}$ and interdiffusion of $\mathrm{Au}$ in $\mathrm{Cu}^{23}$

The previous experiments used solid metal substrates that were heated to temperatures below their melting point. The new experiments with solders required a different sample holder, since samples are molten during portions of the experiment. The first-generation sample holder and experimental setup is described in Ref. 24 and was modified for these new experiments to allow for more uniform heating and more accurate temperature control and measurement. As before, a graphite heater was chosen, since it is easily heated using resistive methods. The heater is illustrated in Fig. 2, measuring $100 \mathrm{~mm}$ long and $8 \mathrm{~mm}$ wide, with an enlarged central section that allows a $6.3-\mathrm{mm}$ diameter substrate to be placed inside. A hole drilled from the back side of the heater allows a thermocouple to be inserted through it. The substrate that fits inside of the heater is illustrated in Fig. 3, having a 5.3-mm-diameter flat surface where the 5-mm-diameter $\mathrm{Sn}$ or In solder disk is placed. A blind hole is drilled from the back side of the substrate to allow the thermocouple to be placed inside of it, close to the location where the solder is melted and solidified. Silver-loaded thermally conductive epoxy is used to hold the thermocouple in the back side of the substrate, while thermally 


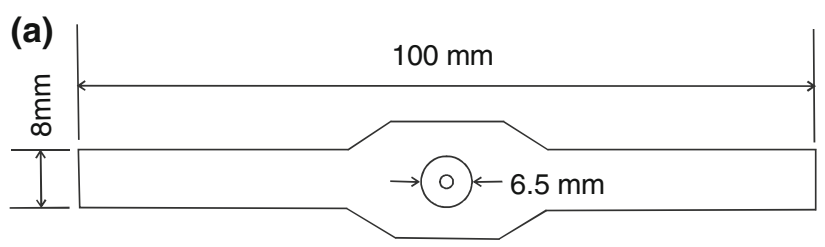

(b)

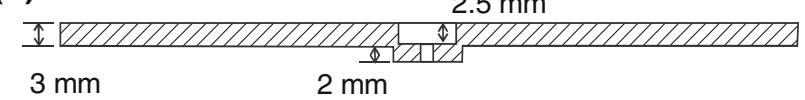

Fig. 2. Graphite heater design: (a) top view, and (b) cross-sectional side view. The circular disk sample is placed in the hole $(6.5 \mathrm{~mm}$ diameter) in the top center of the heater. A small hole is drilled below the sample holder to allow a thermocouple to be inserted into the substrate.

(a)

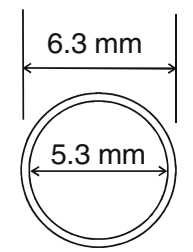

(b)

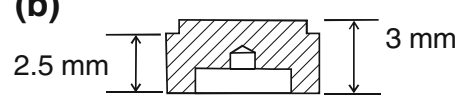

Fig. 3. Schematic drawing of the substrate (graphite, $\mathrm{Cu}$ or $\mathrm{Au} / \mathrm{Ni} /$ $\mathrm{Cu}$ ) that fits inside the heater shown in Fig. 2: (a) top view showing the 5.3-mm-diameter surface where the Sn or In foils are placed, and (b) cross-sectional side view showing the thermocouple well.

conductive silver-loaded paste is used on the bottom and sides of the substrate to ensure good thermal contact between the substrate and the graphite heater.

The alloys used in the experiments consisted of Sn (99.999\% Sn, Alfa Aesar \#38538), In (99.99\% In, Indium Corporation IND\#4), high-purity graphite (ISO 63 fine grained), and oxygen free high conductivity $(\mathrm{OFHC}) \mathrm{Cu}$ substrates. Some of the $\mathrm{Cu}$ substrates were plated using an electrolytic $\mathrm{Ni}$ followed by electrolytic $\mathrm{Au}$ finish $(\mathrm{Au} / \mathrm{Ni} / \mathrm{Cu})$. The thicknesses of the Ni and Au layers were $1 \mu \mathrm{m}$ each. Table I lists the alloys and the thicknesses of each sample. The Sn and In samples were punched into 5-mm-diameter disks in preparation for the experiment.

The Sn and In samples were prepared by first dipping them in a rosin-based mildly active liquid flux (Indium Corporation RMA Flux \#5) to reduce existing oxides and to prevent further reaction during heating. This flux is reported to contain $40 \%$ to $50 \%$ rosin mixture, $30 \%$ to $40 \%$ isopropyl alcohol, $10 \%$ to $30 \%$ methyl ethyl ketone, and $1 \%$ to $2 \%$ proprietary ingredients by weight. The samples were then placed on the top of the substrate with the thermocouple preattached. An adhesive Kapton strip, measuring $100 \mathrm{~mm} \times 8 \mathrm{~mm} \times 0.100 \mathrm{~mm}$,
Table I. Melting temperatures for Sn and In metals, substrates, and eutectic combinations for each of the solder/substrates

\begin{tabular}{|c|c|c|c|}
\hline Alloy & $\begin{array}{c}\text { Composition } \\
(w t . \%)\end{array}$ & $\begin{array}{c}\text { Thickness } \\
(\mu \mathrm{m})\end{array}$ & $\underset{\left({ }^{\circ} \mathbf{C}\right)}{\boldsymbol{T}_{\mathbf{m}}}$ \\
\hline Sn-high purity & $99.999 \mathrm{Sn}$ & 50 & 232.0 \\
\hline In-high purity & $99.99 \mathrm{In}$ & 50 & 156.6 \\
\hline $\mathrm{Cu}$ substrate & $99.95 \mathrm{Cu}$ & 3000 & 1083 \\
\hline Graphite substrate & $99.9 \mathrm{C}$ & 3000 & 3642 \\
\hline $\mathrm{Sn}-\mathrm{Cu}$ eutectic & - & - & 227.0 \\
\hline Sn-Au eutectic & - & - & 217.0 \\
\hline In-Cu eutectic & - & - & 153.0 \\
\hline In-Au eutectic & - & - & 156.0 \\
\hline
\end{tabular}

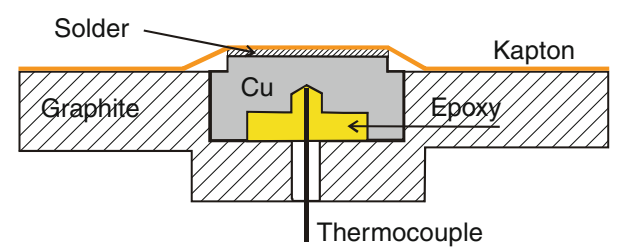

Fig. 4. Schematic cross-sectional side view of the central portion of the graphite heater with a $\mathrm{Cu}$ substrate and solder foil assembled in place. The Sn or In solder foil is pressed down flat on the top surface of the substrate using Kapton film. The thermocouple enters from the bottom of the heater and is held in place in the substrate by thermally conductive epoxy.

was then placed over the top of the substrate to hold the solder foils in place, as illustrated in Fig. 4. The Kapton layer helps keep the surface flat during heating and minimizes liquid solder balling at its center point. The 0.1-mm-thick Kapton film is thin enough to let x-rays pass through it, and does not react with the solder.

The in situ experiments were performed by placing the loaded heater into the water-cooled grips of a heating stage with an angle of $\sim 5^{\circ}$ with respect to the axis of the x-ray beam, and aligned so that the $2 \mathrm{~mm} \times 0.5 \mathrm{~mm}$ beam is centered on the sample. An environmental chamber was then placed over the sample and evacuated to approximately $10 \mathrm{mTorr}$ using a turbomolecular pump to prevent oxidation of the samples during the in situ experiments. The experiment was conducted by heating $\mathrm{Sn}$ and $\mathrm{In}$, to and from their melting points, while observing phase transformations as a function of time and temperature and collecting x-ray diffraction data in real time in a similar fashion as previous work. ${ }^{24}$

\section{RESULTS AND DISCUSSION}

\section{Tin Solidified on Graphite, Gold, and Copper Substrates}

The first set of experiments consisted of melting and solidifying high-purity Sn on graphite. Since graphite and Kapton do not react with $\mathrm{Sn}$, the $\mathrm{Sn}$ melts and solidifies in such a way that any heterogeneous nucleation effects induced by the substrate 


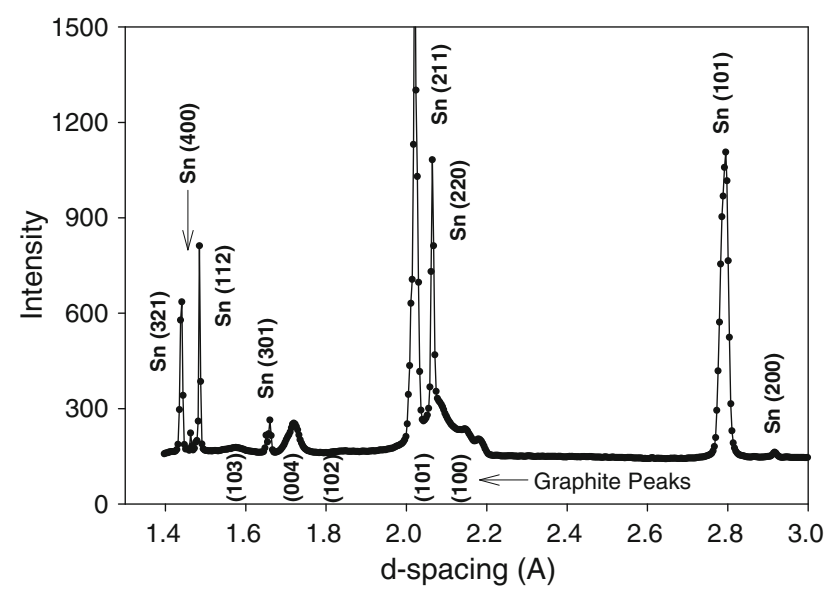

Fig. 5. Initial diffraction pattern of Sn showing the eight major $\mathrm{Sn}$ peaks in the diffraction window. The five possible graphite peaks that can appear in this window are indicated.

are minimized. One would therefore expect the amount of undercooling of the liquid Sn during solidification to be larger than if the Sn was in contact with a reacting substrate such as $\mathrm{Cu}$. The Sn samples were heated at a rate of $1^{\circ} \mathrm{C} / \mathrm{s}$, held at a peak temperature of $257^{\circ} \mathrm{C}$ for $1 \mathrm{~s}$, and then cooled at $1^{\circ} \mathrm{C} / \mathrm{s}$. Thus, the total time spent above the liquidus temperature of $\mathrm{Sn}\left(232^{\circ} \mathrm{C}\right)$ was $50 \mathrm{~s}$, which was sufficient for the Sn to melt and flow to a smaller-diameter shape under the constraining force of the Kapton cover.

Figure 5 shows an initial diffraction pattern for the Sn foil on the graphite substrate at room temperature before heating began. The diffraction pattern is formed by integrating the in situ diffraction rings about their central point to create an intensity versus $d$-spacing plot using FIT2D software available from ESRF. ${ }^{25}$ There are eight Sn diffraction peaks that appear in the $\mathrm{x}$-ray diffraction window, with $d$-spacings between $1.4 \AA$ and $3.0 \AA$. In addition, five possible graphite peaks are present in this window, as indicated. The two most prominent high-angle Sn peaks are $\operatorname{Sn}(200)$ located at $2.916 \AA$ and $\operatorname{Sn}(101)$ located at $2.793 \AA$, as calculated from the lattice parameters of bct Sn for $a=5.8313 \AA$ and $c=3.1815 \AA{ }^{18}$ for the $29.1-\mathrm{keV}$ beam. Texturing of the thin foil results in only the $\operatorname{Sn}(101)$ peak diffracting strongly in this case, and alters the ideal diffraction intensities of the remaining six peaks that appear at lower $d$-spacings.

Figure 6 shows the results from one of the in situ $\mathrm{x}$-ray diffraction runs where the Sn was melted and solidified on the graphite. In this figure, more than 200 individual diffraction patterns are plotted sequentially in time along the $y$-axis versus $d$-spacing along the $x$-axis. The diffraction patterns are plotted in pseudocolor, such that higher intensities are shown in light color, and low intensities are dark. The experiment starts at $t=0 \mathrm{~s}$, where all of the Sn diffraction peaks are present as indicated in Fig. 5. Sequential diffraction patterns are taken approximately every $2 \mathrm{~s}$, and heating begins at approximately $t=80 \mathrm{~s}$, which is marked as "a" in the figure. At this point the temperature begins to ramp at $1^{\circ} \mathrm{C} / \mathrm{s}$, as indicated by the corresponding temperature profile plotted to the right. As heating continues, the Sn peaks shift to higher $d$-spacings due to the lattice expansion. Grains in the Sn foil recrystallize and/or grow, creating a new texture which causes many of the peaks to diminish and/or disappear around $t=250 \mathrm{~s}$, when the temperature is approximately $180^{\circ} \mathrm{C}$, and marked " $\mathrm{b}$ " on the figure. The sample continues to heat and eventually melts just before $t=300 \mathrm{~s}$ at a temperature of $232.8^{\circ} \mathrm{C}$, as indicated by point "c" on the figure. Melting is identified by the sudden change in
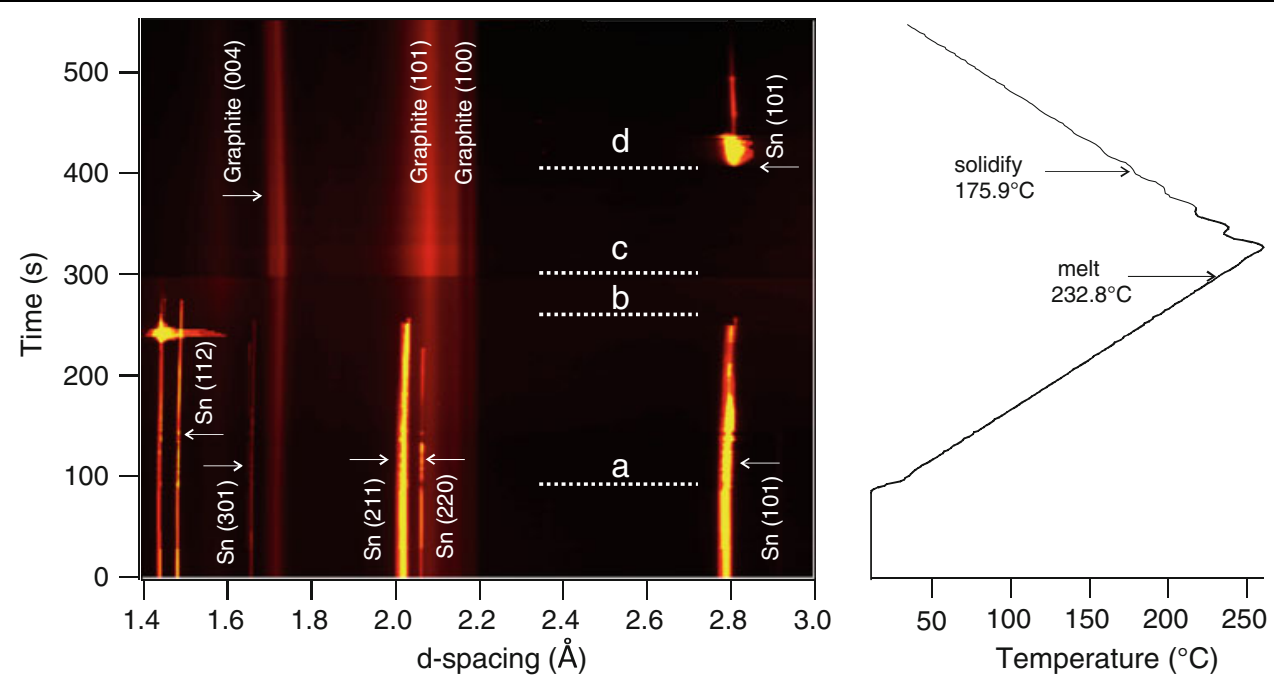

Fig. 6. In situ $\mathrm{x}$-ray diffraction patterns for $\mathrm{Sn}$ on graphite. The $y$-axis sequentially plots diffraction patterns starting from the initiation of heating to the point where solidification is complete on cooling. Heating begins at "a," grain growth and texturing results in the loss of many Sn diffraction peaks at "b," melting occurs at "c," and solidification occurs at "d" when the Sn(101) reflection reappears. 
background intensity and the appearance of more intense diffraction peaks from the graphite substrate. The sample heats to its peak temperature and cools from there at $1{ }^{\circ} \mathrm{C} / \mathrm{s}$. During cooling the solder passes below its melting point and continues to cool until $t=400 \mathrm{~s}$, marked "d" on the figure, where Sn solidifies with the appearance of a strong $\operatorname{Sn}(101)$ peak at a temperature of $175.9^{\circ} \mathrm{C}$. The undercooling, defined as the difference between the equilibrium melting temperature $\left(232.0^{\circ} \mathrm{C}\right)$ and the solidification temperature, is $56.1^{\circ} \mathrm{C}$ in this experiment and represents a large undercooling of Sn before solidification occurred.

Note that, although this run is very typical of the type of data that are collected, it is somewhat unusual in the high intensity of the Sn diffraction peak that appeared on solidification. Due to the small number of diffracting grains in the highly undercooled and solidified Sn, there is a statistical nature to the diffraction peaks that appear on solidification, and in this case, the Sn solidified by chance with the strongly diffracting $\operatorname{Sn}(101)$ peak reflecting directly into the detector, making it very clear when solidification occurred. In other experiments, it is often necessary to examine the appearance of smaller peaks and changes in background intensity to determine the exact point of solidification. Another point of note is that there are some temperature instabilities in the cooling of this sample, caused by a new temperature controller that was not yet tuned to the system. These instabilities are not considered significant in terms of the amount of undercooling observed.

Two additional experiments were performed on Sn to observe melting and solidification on graphite.
All three runs had similar results, which are summarized in Table II. The three experiments gave undercoolings of $41.4^{\circ} \mathrm{C}, 51.5^{\circ} \mathrm{C}$, and $56.1^{\circ} \mathrm{C}$, for an average undercooling of $49.7^{\circ} \mathrm{C}$. These results confirm the large undercooling of $\mathrm{Sn}$ on nonwetting surfaces. ${ }^{2,3}$ The large variation in the undercooling results are most likely due to the statistical nature of nucleation of undercooled melts, where surface tension, number density of nucleation sites, and geometrical shape of the melt can all influence the amount of undercooling prior to solidification.

Figure 7 shows similar experiments that were performed with $\mathrm{Sn}$ on Au-coated $\mathrm{Cu}$ substrates to observe the influence of a wetting substrate on undercooling. These samples were heated and cooled at $1^{\circ} \mathrm{C} / \mathrm{s}$, with an identical time-temperature profile as the samples heated and cooled on graphite. The experiment starts at $t=0 \mathrm{~s}$, where the $\mathrm{Sn}$ diffraction peaks are clearly present. Sequential diffraction patterns are taken approximately every $2 \mathrm{~s}$, and heating begins at approximately $t=50 \mathrm{~s}$, which is marked as "a" in the figure. At this point the temperature begins to ramp at $1^{\circ} \mathrm{C} / \mathrm{s}$, as indicated by the corresponding temperature profile plotted to the right. As heating continues, the Sn peaks shift to higher $d$-spacings due to the lattice expansion. Grains in the Sn foil recrystallize and/or grow, creating a new texture which causes many of the peaks to diminish and/or disappear around $t=220 \mathrm{~s}$, when the temperature is approximately $200^{\circ} \mathrm{C}$, marked "b" on the figure. The sample continues to heat and eventually melts at about $t=230 \mathrm{~s}$ at a temperature of $228.1^{\circ} \mathrm{C}$, as indicated by point "c" on the figure. Melting of the Sn is again identified by the change in the background intensity

Table II. Summary of measured undercooling $(\Delta T)$ of $\mathrm{Sn}$ and $\mathrm{In}$ on graphite, $\mathrm{Cu}$, and $\mathrm{Au} / \mathrm{Ni} / \mathrm{Cu}$ substrates

\begin{tabular}{|c|c|c|c|c|c|c|}
\hline Sample ID & Substrate & $\boldsymbol{T}_{\mathrm{m}}\left({ }^{\circ} \mathbf{C}\right)$ & $T_{\mathrm{s}}\left({ }^{\circ} \mathrm{C}\right)$ & $\boldsymbol{T}_{\mathbf{0}}\left({ }^{\circ} \mathbf{C}\right)$ & $\Delta T\left(T_{0}-\mathbf{T}_{\mathbf{s}}\right)\left({ }^{\circ} \mathbf{C}\right)$ & $\Delta T$ avg. $\left({ }^{\circ} \mathbf{C}\right)$ \\
\hline Sn-1 & Graphite & 231.9 & 190.6 & 232.0 & 41.4 & 49.7 \\
\hline $\mathrm{Sn}-2$ & Graphite & 240.8 & 180.5 & 232.0 & 51.5 & \\
\hline Sn-3 & Graphite & 232.8 & 175.9 & 232.0 & 56.1 & \\
\hline $\mathrm{SnAu-1}$ & $\mathrm{Au} / \mathrm{Ni} / \mathrm{Cu}$ & 229.1 & 193.0 & 217.0 & 24.0 & 17.3 \\
\hline $\mathrm{SnAu-2}$ & $\mathrm{Au} / \mathrm{Ni} / \mathrm{Cu}$ & 228.1 & 204.1 & 217.0 & 12.9 & \\
\hline SnAu-3 & $\mathrm{Au} / \mathrm{Ni} / \mathrm{Cu}$ & 233.9 & 202.0 & 217.0 & 15.0 & \\
\hline $\mathrm{SnCu}-1$ & $\mathrm{Cu}$ & 227.9 & 219.8 & 227.0 & 7.2 & 10.5 \\
\hline $\mathrm{SnCu}-2$ & $\mathrm{Cu}$ & 228.3 & 215.8 & 227.0 & 11.2 & \\
\hline $\mathrm{SnCu}-3$ & $\mathrm{Cu}$ & 233.4 & 213.8 & 227.0 & 13.2 & \\
\hline In-1 & Graphite & 160.0 & 154.0 & 156.6 & 3.4 & 2.8 \\
\hline In-2 & Graphite & 158.0 & 153.0 & 156.6 & 1.4 & \\
\hline In-3 & Graphite & 160.4 & 151.3 & 156.6 & 3.8 & \\
\hline In-4 & Graphite & 156.9 & 154.1 & 156.6 & 2.5 & \\
\hline InAu-1 & $\mathrm{Au} / \mathrm{Ni} / \mathrm{Cu}$ & 159.9 & 153.2 & 156.0 & 2.8 & 2.0 \\
\hline InAu-2 & $\mathrm{Au} / \mathrm{Ni} / \mathrm{Cu}$ & 156.9 & 155.1 & 156.0 & 0.9 & \\
\hline InAu-3 & $\mathrm{Au} / \mathrm{Ni} / \mathrm{Cu}$ & 161.5 & 153.7 & 156.0 & 2.3 & \\
\hline InCu-1 & $\mathrm{Cu}$ & 162.2 & 152.6 & 153.0 & 0.4 & -0.7 \\
\hline InCu-2 & $\mathrm{Cu}$ & 162.0 & 154.0 & 153.0 & -1.0 & \\
\hline
\end{tabular}

Undercooling is calculated relative to the melting temperature of the metals on graphite, or the eutectic temperature on metal substrates indicated as $T_{0}$. All experiments were performed at cooling rate of $1^{\circ} \mathrm{C} / \mathrm{s}$ 

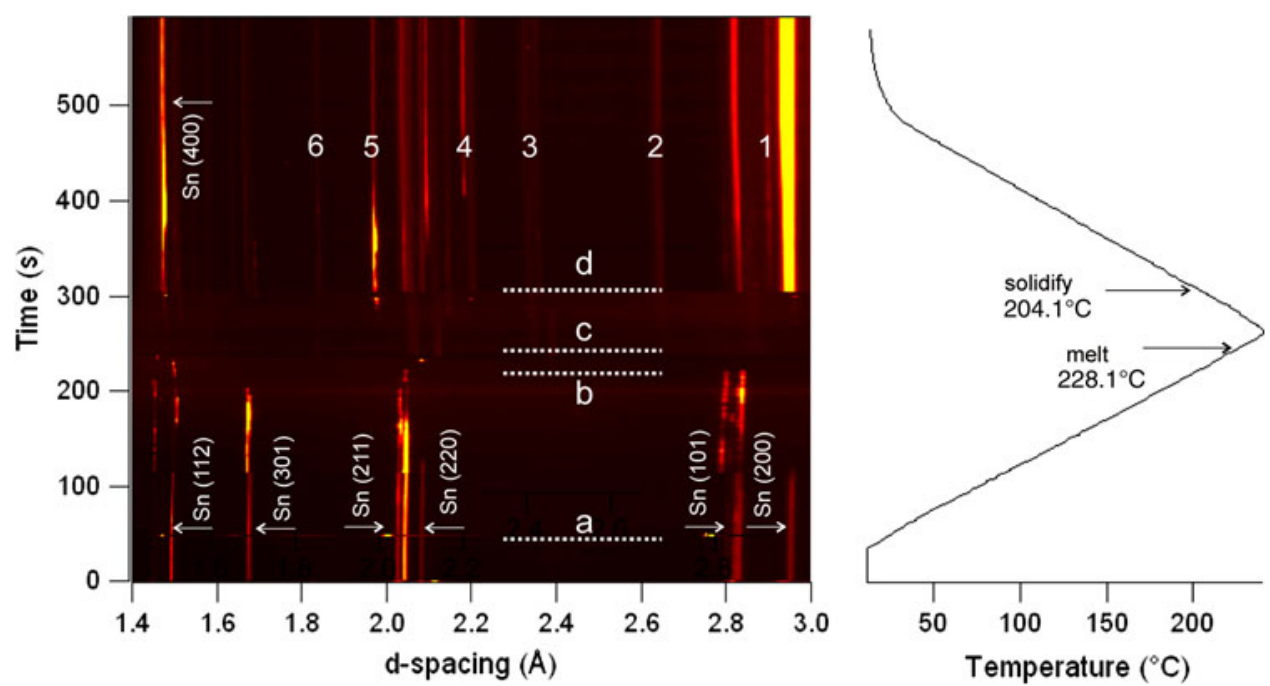

Fig. 7. In situ x-ray diffraction patterns for $\mathrm{Sn}$ on $\mathrm{Au}$. The $y$-axis sequentially plots diffraction patterns starting from the initiation of heating to the point where solidification is complete on cooling. Heating begins at "a," grain growth and texturing results in the loss of many Sn diffraction peaks at "b," melting occurs at "c," and solidification occurs at "d" when the Sn(200) and Sn(101) reflections reappear. The numbers 1-6 indicate new diffraction peaks related to the Au-Sn intermetallic phase.

combined with the disappearance of the remaining Sn peaks. The sample heats to its peak temperature and cools from there at $1^{\circ} \mathrm{C} / \mathrm{s}$. During cooling the solder passes below its melting point and continues to cool until $t=300 \mathrm{~s}$, marked "d" on the figure, where Sn solidifies with the strong appearance of the $\operatorname{Sn}(200)$ and $\operatorname{Sn}(101)$ peaks at a temperature of $204.1^{\circ} \mathrm{C}$. The undercooling, defined as the difference between the $\mathrm{Au}-\mathrm{Sn}$ eutectic $\left(217.0^{\circ} \mathrm{C}\right)$ and the solidification temperature, is $12.9^{\circ} \mathrm{C}$ in this experiment. This experiment was repeated two additional times as summarized in Table II, with an average undercooling of $17.3^{\circ} \mathrm{C}$ below the Au-Sn eutectic temperature.

Unlike Sn solidified on graphite, additional peaks appear after melting of the $\mathrm{Sn}$ on Au-coated $\mathrm{Cu}$ substrates and continue to be present during solidification. The major additional peaks are identified with numbers 1-6 in Fig. 7. To help identify these peaks, conventional x-ray diffraction analysis was later performed on one of the Sn samples melted on a $\mathrm{Au} / \mathrm{Ni} / \mathrm{Cu}$ substrate as a postsynchrotron experiment. The results clearly showed the presence of the hexagonal NiAs-type structure (hP4) with lattice parameters $a=4.22 \AA$ and $c=5.08 \AA$. AuSn forms the NiAs structure, and $\mathrm{Cu}_{6} \mathrm{Sn}_{5}$ forms an ordered superstructure of the NiAs structure; the lattice parameters match those of the $\mathrm{Cu}_{6} \mathrm{Sn}_{5}$ subcell $(a=4.19 \AA, c=5.04 \AA)$, not those of AuSn $(a=4.32$ $\AA, c=5.52 \AA) .{ }^{26,27}$ This $\mathrm{Cu}_{6} \mathrm{Sn}_{5}$ structure accounts for peaks 1, 2, and 6 in Fig. 7. Cu but not $\mathrm{Au}$ is observed, so we conclude that the thin $\mathrm{Au}$ (and $\mathrm{Ni}$ ) layers have dissolved or interdiffused, exposing the underlying $\mathrm{Cu}$ to $\mathrm{Sn}$. The remaining peaks $(3,4$, and 5) are most likely due to a $\mathrm{Au} / \mathrm{Ni}$-containing structure which we are unable to identify. These peaks may be related to the Au-Sn intermetallic compounds that have higher melting points than $\mathrm{Sn}^{15}$ and formed quickly during the experiment. Other possible intermetallics in the $\mathrm{Sn} / \mathrm{Au}-\mathrm{Ni}-\mathrm{Cu}$ system with the same crystal structure include $\mathrm{AuCuSn}_{2}$ and $\mathrm{AuNiSn}_{2}$.

Figure 8 shows the last set of experiments on Sn, performed on pure $\mathrm{Cu}$ substrates. The experiment starts at $t=0 \mathrm{~s}$, where the Sn diffraction peaks are clearly present. Sequential diffraction patterns are taken approximately every $2 \mathrm{~s}$, and heating begins at approximately $t=40 \mathrm{~s}$, which is marked as "a" in the figure. At this point the temperature begins to ramp at $1^{\circ} \mathrm{C} / \mathrm{s}$, as indicated by the corresponding temperature profile plotted to the right. Grains in the Sn foil recrystallize and/or grow, creating a new texture at temperatures as low as $100^{\circ} \mathrm{C}$. The texture increases, and at $t=240 \mathrm{~s}$, when the temperature is approximately $200^{\circ} \mathrm{C}$, only one or two diffraction planes appear, as indicated by "b" on the figure. The sample continues to heat and eventually melts at a temperature of $233.4^{\circ} \mathrm{C}$, as indicated by point "c" on the figure. Melting of the Sn is again identified by the change in the background intensity combined with the disappearance of the remaining Sn peaks. The sample heats to its peak temperature and cools from there at $1{ }^{\circ} \mathrm{C} / \mathrm{s}$. During cooling the solder passes below its melting point and continues to cool until $t=320 \mathrm{~s}$, marked "d" on the figure, where Sn solidifies with the appearance of the $\mathrm{Sn}(200)$ and $\mathrm{Sn}(101)$ peaks at a temperature of $213.8^{\circ} \mathrm{C}$. The undercooling in this experiment was $13.2^{\circ} \mathrm{C}$ below the $\mathrm{Cu}-\mathrm{Sn}$ eutectic. This experiment was repeated two additional times as summarized in Table II, with an average undercooling of $10.5^{\circ} \mathrm{C}$ below the $\mathrm{Sn}-\mathrm{Cu}$ eutectic temperature. 

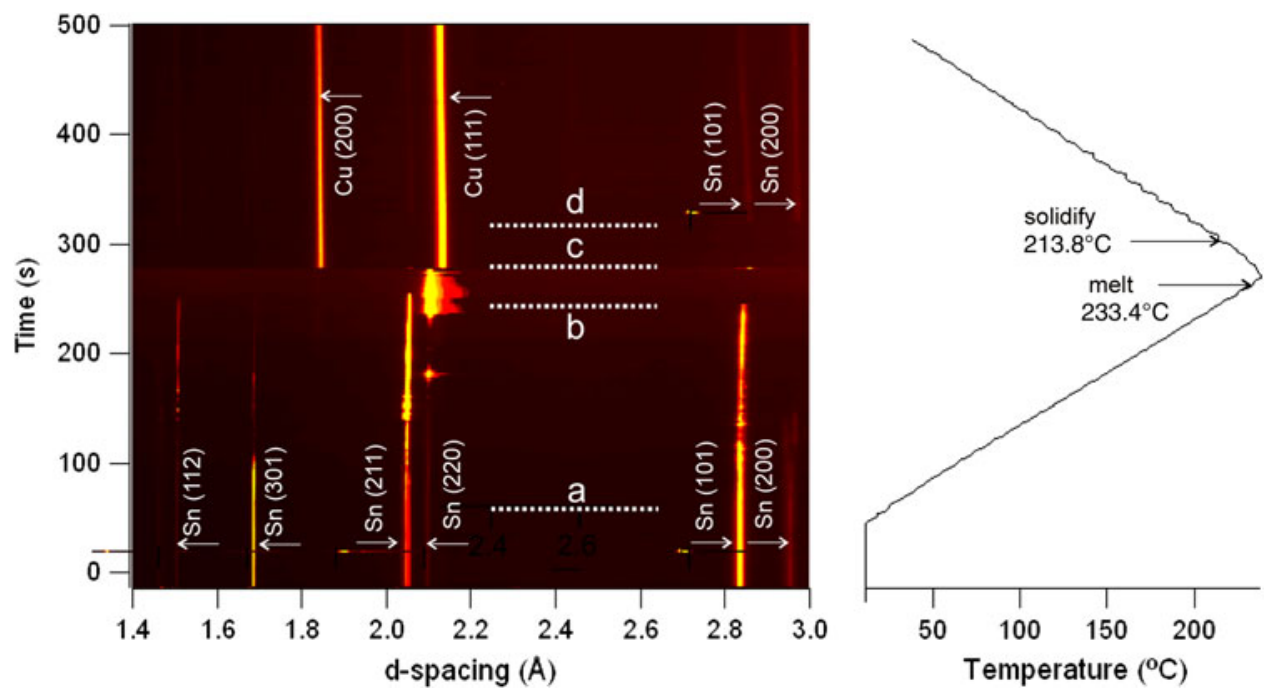

Fig. 8. In situ x-ray diffraction patterns for $\mathrm{Sn}$ on $\mathrm{Cu}$. The $y$-axis sequentially plots diffraction patterns starting from the initiation of heating to the point where solidification is complete on cooling. Heating begins at "a," grain growth and texturing results in the loss of many Sn diffraction peaks at "b," melting occurs at "c," and solidification occurs at "d" when the $\mathrm{Sn}(101)$ and $\mathrm{Sn}(200)$ reflections reappear.

\section{Indium Solidified on Graphite, Gold, and Copper Substrates}

The next set of experiments was performed with In on graphite substrates, also with a Kapton film holding down the In, as illustrated in Fig. 4. The samples were heated at a rate of $1^{\circ} \mathrm{C} / \mathrm{s}$, held at peak temperature of $180^{\circ} \mathrm{C}$ for $1 \mathrm{~s}$, and then cooled at $1^{\circ} \mathrm{C} / \mathrm{s}$. Thus the total time spent above the liquidus temperature of In $\left(156.6^{\circ} \mathrm{C}\right)$ was $50 \mathrm{~s}$, which is sufficient for the In to melt and flow to a smallerdiameter shape under the constraining force of the Kapton cover.

Figure 9 shows an initial diffraction pattern for the In foil on the graphite substrate at room temperature before heating began. There are seven In diffraction peaks that appear in the x-ray diffraction window, with $d$-spacings between $1.39 \AA$ and $2.80 \AA$. In addition, five possible graphite peaks are present in this window as indicated. The three most prominent In peaks are $\operatorname{In}(101)$ located at $2.7178 \AA$, $\operatorname{In}(002)$ located at $2.4728 \AA$, and $\operatorname{In}(211)$ located at $1.3957 \AA$ as calculated from the lattice parameters of bct In for $a=3.2430 \AA$ and $c=4.9455 \AA{ }^{16}$ Texturing of the thin foil alters the diffraction intensities of the peaks.

Figure 10 shows the results from one of the in situ x-ray diffraction runs where the In was melted and solidified on the graphite. During heating, the In peaks shift $d$-spacings with temperature, but note that the $\operatorname{In}(002)$ moves to lower $d$-spacings with increasing temperature, as discussed below. Grains in the In foil recrystallize and/or grow, causing some peaks to diminish and/or disappear around $t=150 \mathrm{~s}$, when the temperature is $135^{\circ} \mathrm{C}$. The sample continues to heat and eventually melts at $t=175 \mathrm{~s}$ at a temperature of $156.9^{\circ} \mathrm{C}$, as indicated by point "c" on the figure. The sample heats to

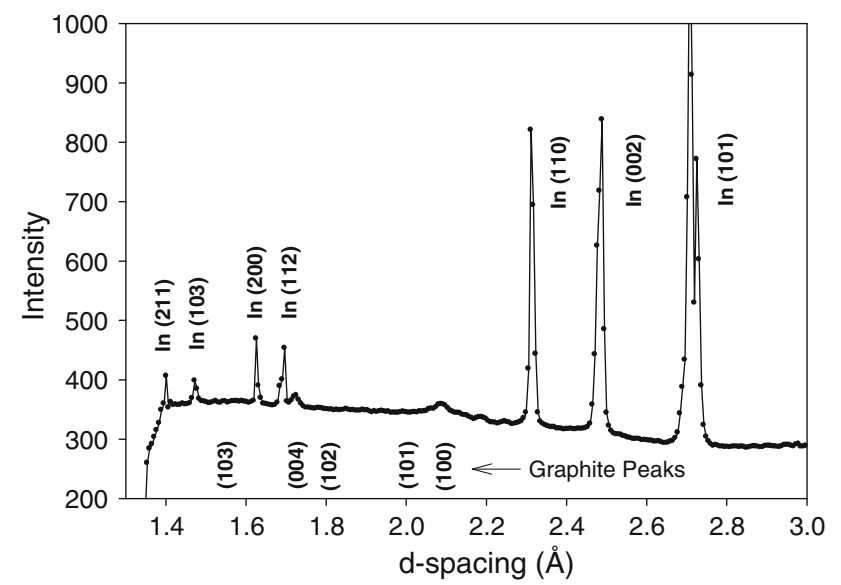

Fig. 9. Initial diffraction pattern for In showing the seven major peaks in the diffraction window. The five possible graphite peaks that can appear in this window are indicated.

its peak temperature and then cools at a rate of $1^{\circ} \mathrm{C} /$ s. During cooling the solder passes below its melting point and continues to cool until $t=200 \mathrm{~s}$, marked "d" on the figure, where In solidifies at $154.1^{\circ} \mathrm{C}$, as determined by the change in background intensity. The undercooling of this sample is $2.5^{\circ} \mathrm{C}$ below the equilibrium melting point of $\operatorname{In}\left(156.6^{\circ} \mathrm{C}\right)$. Three additional experiments were performed on In to observe melting and solidification on graphite, as indicated in Table II. The average undercooling for the four experiments is $2.8^{\circ} \mathrm{C}$ for In on graphite, which is considerably less than what was observed on any of the Sn samples.

Figure 11 shows the results from one of the in situ x-ray diffraction runs where the In was melted and solidified on $\mathrm{Au} / \mathrm{Ni} / \mathrm{Cu}$. This figure, like the others, displays the sequence of diffraction patterns 

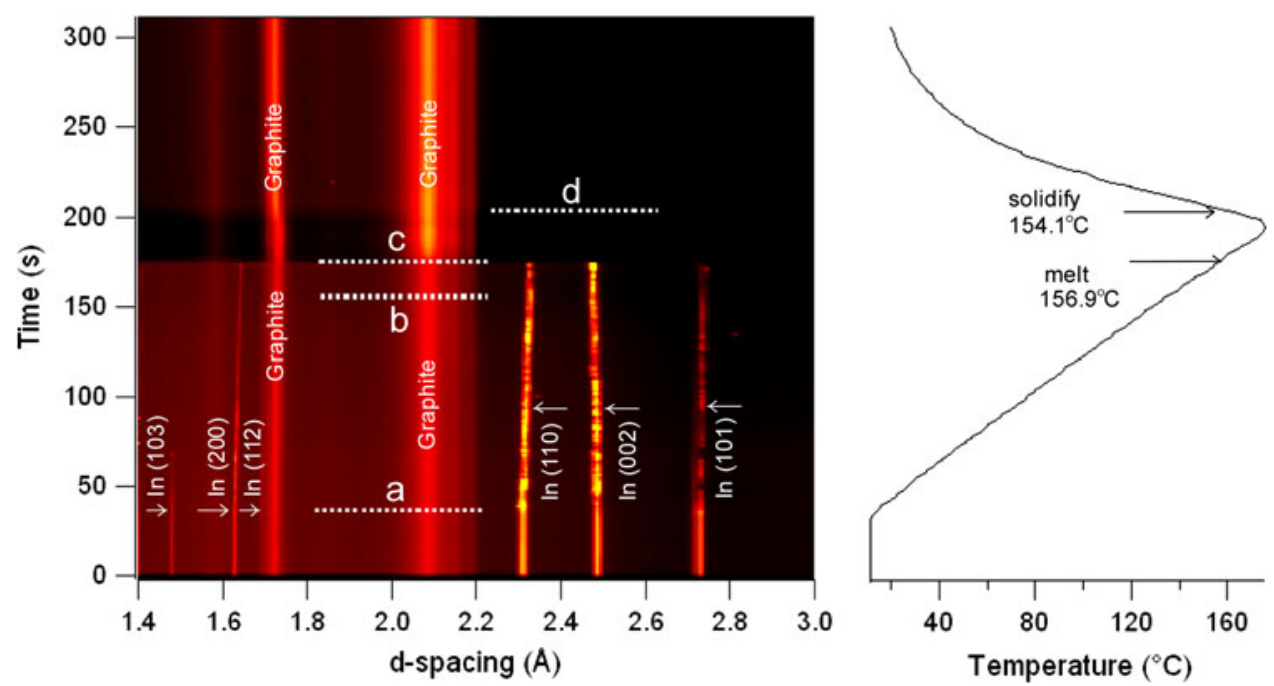

Fig. 10. In situ x-ray diffraction patterns for In on graphite. The $y$-axis sequentially plots the diffraction patterns starting from the initiation of heating to the point where solidification is complete on cooling. Heating begins at "a," grain growth and texturing results in the loss of some diffraction peaks at "b," melting occurs at "c," and solidification occurs at "d" with a change in the intensity of the background.
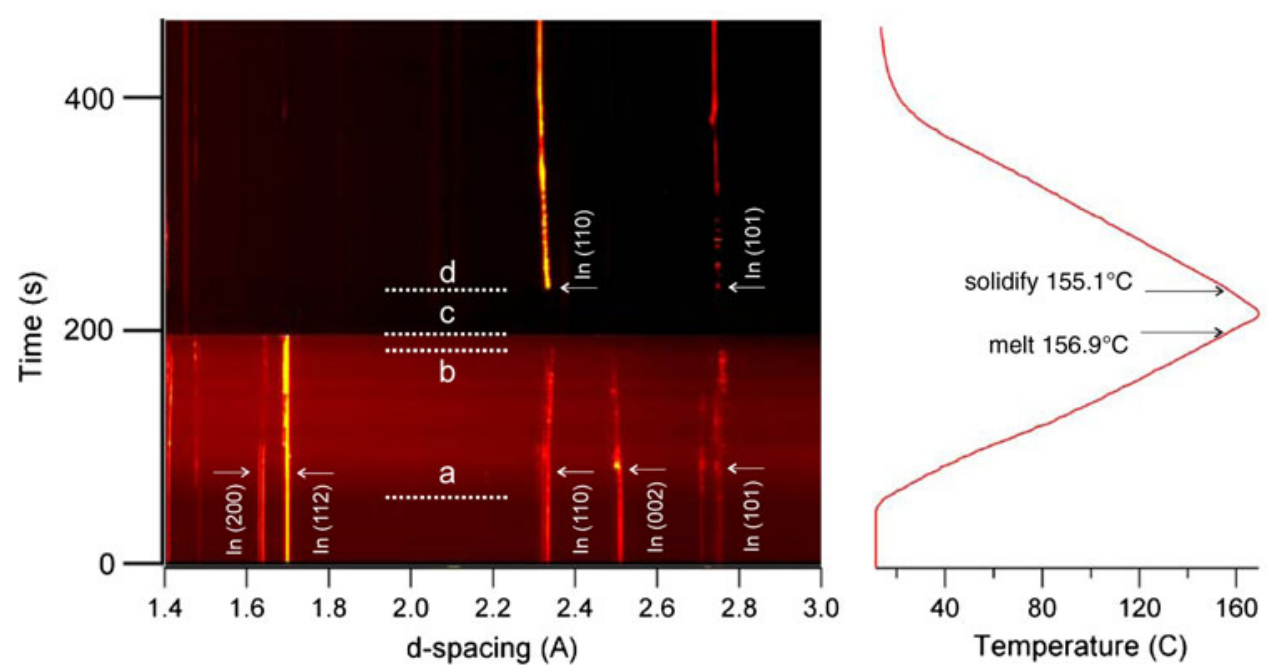

Fig. 11. In situ x-ray diffraction patterns for In on Au. The $y$-axis sequentially plots diffraction patterns starting from the initiation of heating to the point where solidification is complete on cooling. Heating begins at "a," grain growth and texturing results in the loss of many Sn diffraction peaks at "b," melting occurs at "c," and solidification occurs at "d" when the $\ln (110)$ and $\ln (101)$ reflections reappear.

on the left and the temperature profile on the right. The experiment starts with textured In such that the $\operatorname{In}(112)$ plane is the most intense. Heating begins at $t=40 \mathrm{~s}$, marked "a" on the figure. Heating continues with the diffracting planes shifting lattice spacings as the temperature is increased. Around $t=160 \mathrm{~s}$, some of the diffracting planes begin to lose intensity, and at $t=184 \mathrm{~s}$, marked " $\mathrm{b}$ " in the figure, many of the planes have disappeared due to additional grain growth and texturing. Melting occurs at $t=198 \mathrm{~s}$, marked "c" in the figure when the temperature has reached $156.9^{\circ} \mathrm{C}$. Approximately $40 \mathrm{~s}$ later, after the temperature has passed its peak and the sample is cooling down, solidification occurs when the temperature is $155.1^{\circ} \mathrm{C}$ as indicated by the sharp appearance of the $\operatorname{In}(110)$ and $\operatorname{In}(101)$ planes. The solidification temperature is only $1.5^{\circ} \mathrm{C}$ below the equilibrium melting temperature of In, corresponding to undercooling of only $0.9^{\circ} \mathrm{C}$ below the $\mathrm{Au}-\mathrm{In}$ eutectic temperature. This experiment was repeated two additional times, as summarized in Table II, showing an average undercooling of only $2.0^{\circ} \mathrm{C}$ below the $\mathrm{Au}$-In eutectic temperature.

Figure 12 shows the results from one of the in situ x-ray diffraction runs where the In was melted and solidified on pure $\mathrm{Cu}$. Heating begins at $t=30 \mathrm{~s}$, marked "a" on the figure, and continues at $1^{\circ} \mathrm{C} / \mathrm{s}$ with the diffracting planes shifting lattice spacings as the temperature is increased. Around $t=160 \mathrm{~s}$, some of the diffracting planes begin to lose 

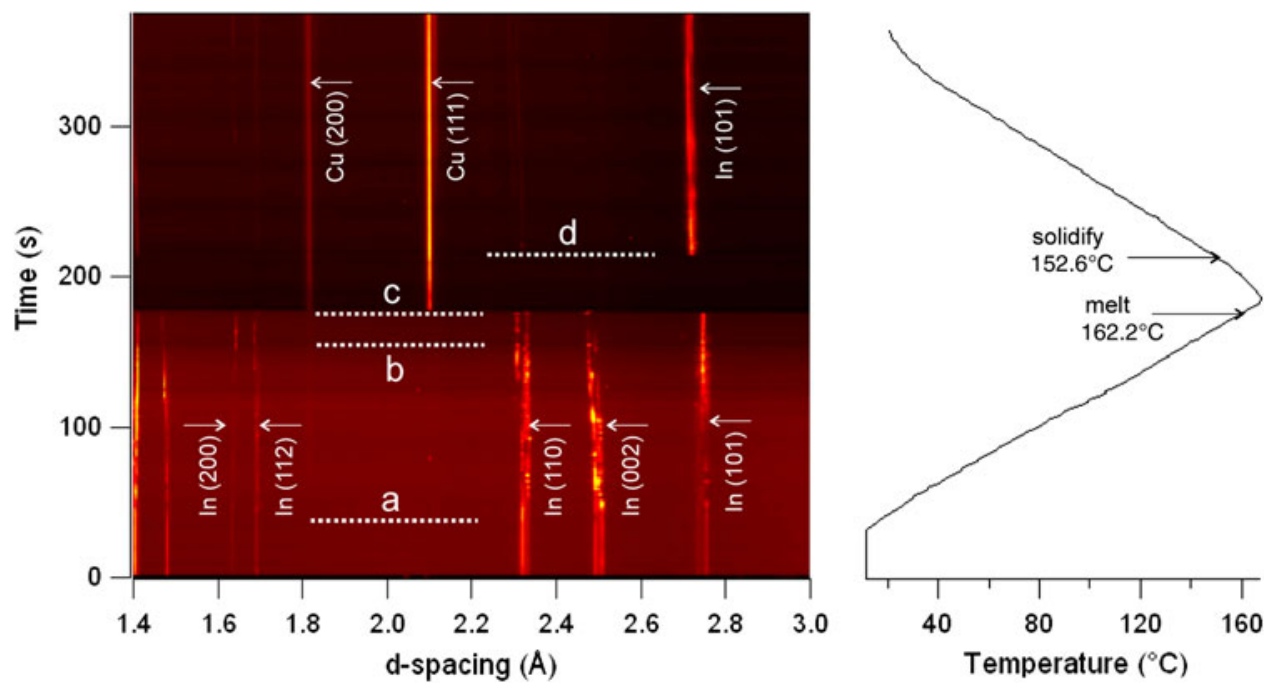

Fig. 12. In situ x-ray diffraction patterns for In on $\mathrm{Cu}$. The $y$-axis sequentially plots diffraction patterns starting from the initiation of heating to the point where solidification is complete on cooling. Heating begins at "a," grain growth and texturing results in the loss of many Sn diffraction peaks at "b," melting occurs at "c," and solidification occurs at "a" when the In(101) reflection reappears.

intensity, marked "b" in the figure. Melting occurs at $t=180 \mathrm{~s}$, marked "c" in the figure, when the temperature has reached $162.2^{\circ} \mathrm{C}$. Approximately $30 \mathrm{~s}$ later, after the temperature has passed its peak and the sample is cooling down, solidification occurs when the temperature is $152.6^{\circ} \mathrm{C}$, as indicated by the sharp appearance of the $\operatorname{In}(101)$ plane. Peaks from the copper substrate also show up at this point as the molten solder moves and does not completely cover the beam, exposing the copper substrate to the beam. The solidification temperature is only $4.0^{\circ} \mathrm{C}$ below the equilibrium melting temperature of In, but only $0.4^{\circ} \mathrm{C}$ below the $\mathrm{Cu}$-In eutectic temperature. This experiment was repeated one additional time, as summarized in Table II. During this second run, the measured solidification temperature was $1.0^{\circ} \mathrm{C}$ above the eutectic temperature, which is $2.3^{\circ} \mathrm{C}$ below the melting point of pure In.

The results of the in situ diffraction experiments on Sn and In show differences in the amounts of undercooling during solidification between the two metals and further differences resulting from the substrates with which they are in contact. Sn clearly displays the largest undercoolings, and the results presented here are consistent with published literature. Indium, on the other hand, displays very little undercooling and solidifies close to its equilibrium melting point on all of the surfaces studied. Reducing the amount of undercooling of Sn and Sn-based solder alloys prior to solidification is an area of great interest to improve mechanical properties of lead-free joints, ${ }^{4-14}$ and future work is planned to use the in situ diffraction experiments developed here to investigate the influence of various inoculants on reducing undercooling in Sn and Sn-based solder alloys.

\section{In Situ Measurements of Thermal Expansion of Sn, In, and IMCs}

In addition to measuring phases present during the heating and cooling, lattice parameters were measured for Sn and In. Both elements display anisotropic expansion behavior, and lattice parameters were measured along both the $a$ and $c$ principal directions of their tetragonal crystal structures. Figure 13a and b show the $a$ and $c$ lattice parameters, respectively, for $\mathrm{Sn}$ measured on graphite during heating, based on the $\operatorname{Sn}(101)$ and $\operatorname{Sn}(200)$ planes. Both the $a$ lattice parameter, i.e., in the basal plane, and the $c$ lattice parameter, i.e., perpendicular to the basal plane, show nonlinear behavior. Scatter in the data at low temperatures prevented a nonlinear fit, so the expansion

Table III. Summary of CTE measured for Sn and In along the principal directions of the tetragonal structure

\begin{tabular}{|c|c|c|c|c|c|}
\hline \multirow[t]{2}{*}{ Description } & \multicolumn{2}{|c|}{$\begin{array}{l}\text { CTE Based on } a \text { Lattice } \\
\text { Parameter }\left(10^{-6 /{ }^{\circ}} \mathbf{C}\right)\end{array}$} & \multicolumn{2}{|c|}{$\begin{array}{l}\text { CTE Based on } c \text { Lattice } \\
\text { Parameter }\left(10^{-6 /{ }^{\circ}} \mathbf{C}\right)\end{array}$} & \multirow{2}{*}{$\frac{\boldsymbol{c} / \boldsymbol{a} \text { Ratio }}{25^{\circ} \mathrm{C} ; 150^{\circ} \mathrm{C}}$} \\
\hline & $25-80^{\circ} \mathrm{C}$ & $T>80^{\circ} \mathrm{C}$ & $25-80^{\circ} \mathrm{C}$ & $T>80^{\circ} \mathrm{C}$ & \\
\hline $\mathrm{Sn}$ & 13.4 & 23.4 & 39.2 & 57.1 & $0.546 ; 0.548$ \\
\hline In & \multicolumn{2}{|c|}{61.3} & -11.1 & -50.5 & $1.528 ; 1.506$ \\
\hline
\end{tabular}



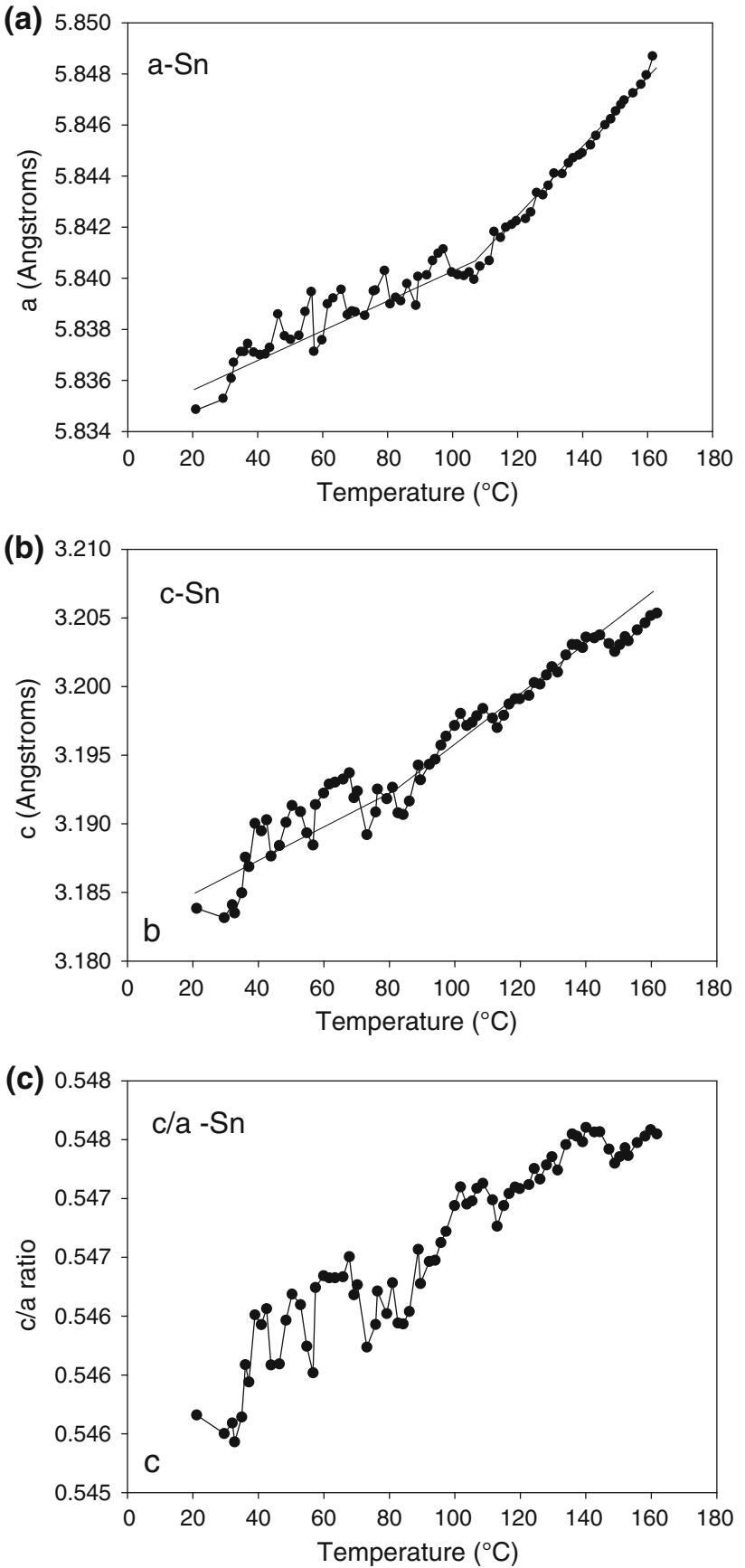

Fig. 13. Lattice spacing of Sn from run Sn-3 (Fig. 6) showing: (a) expansion of the a lattice parameter based on the $S n(220)$ planes, (b) expansion of the $c$ lattice parameter based on the $\mathrm{Sn}(101)$ plane, and (c) the $\mathrm{cla}$ ratio, which increases as the temperature is increased.

coefficient (CTE) was estimated by two linear portions, below and above $80^{\circ} \mathrm{C}$. The $a$ lattice parameter has a measured CTE of $13.7 \times 10^{-6} /{ }^{\circ} \mathrm{C}$ below $80^{\circ} \mathrm{C}$, and $23.4 \times 10^{-6} /{ }^{\circ} \mathrm{C}$ above $80^{\circ} \mathrm{C}$, as summarized in Table III. These values are slightly lower than published values for pure Sn, which also shows nonlinear behavior. ${ }^{28}$ Expansion of the $c$ lattice parameter yields a CTE of $39.2 \times 10^{-6} /{ }^{\circ} \mathrm{C}$ below
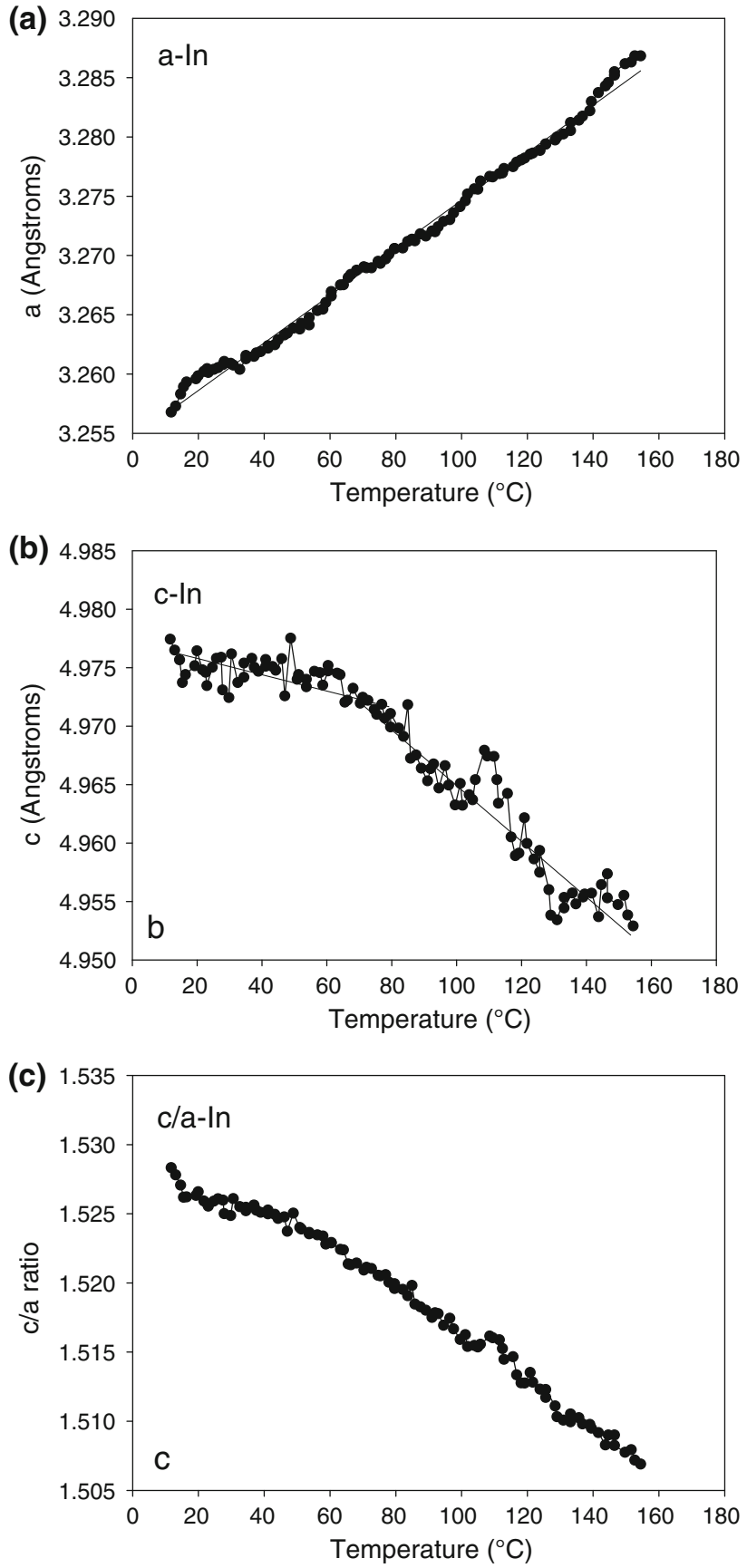

Fig. 14. Lattice spacing of In from run In-4 (Fig. 10) showing: (a) expansion of the a lattice parameter based on the $\ln (200)$ plane, (b) contraction of the $c$ lattice parameter based on the $\ln (002)$ plane, and (c) the ratio of $c / a$, showing a decrease as the temperature is increased.

$80^{\circ} \mathrm{C}$, and $57.1 \times 10^{-6} /{ }^{\circ} \mathrm{C}$ above $80^{\circ} \mathrm{C}$. These data nicely match published data for pure $\mathrm{Sn}^{28}$ The c/a ratio for $\mathrm{Sn}$ is shown in Fig. 13c, exhibiting a slight increasing trend from 0.546 to 0.548 as the temperature increases from $22^{\circ} \mathrm{C}$ to $160^{\circ} \mathrm{C}$.

Figure $14 \mathrm{a}$ and $\mathrm{b}$ show the $a$ and $c$ lattice parameters, respectively, for In, measured on graphite during heating, based on the $\operatorname{In}(200)$ and 


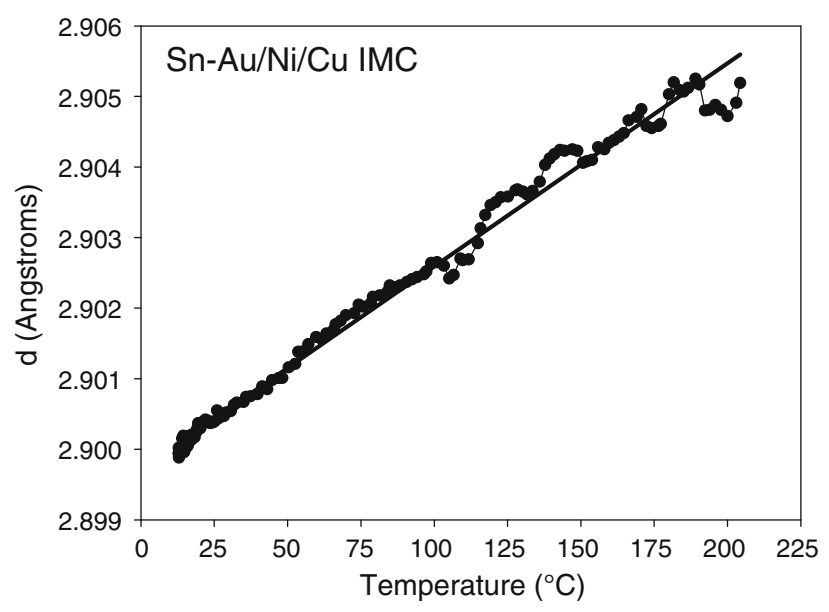

Fig. 15. $d$-Spacing of the intermetallic phase formed on the Sn-Au/ $\mathrm{Ni} / \mathrm{Cu}$ sample. The diffraction peak is marked "1" on Fig. 7, and corresponds to the $\mathrm{Cu}_{6} \mathrm{Sn}_{5}(101)$ plane.

$\operatorname{In}(002)$ planes. The $a$ lattice parameter expansion is linear over the entire temperature range, with a measured CTE of $61.3 \times 10^{-6} /{ }^{\circ} \mathrm{C}$. This value matches the published data for pure In almost exactly. ${ }^{29}$ The $c$ lattice parameter displays nonlinear behavior with a negative expansion coefficient measured as $-11.1 \times 10^{-6} /{ }^{\circ} \mathrm{C}$ from $12^{\circ} \mathrm{C}$ to $80^{\circ} \mathrm{C}$, and $-50.5 \times$ $10^{-6} /{ }^{\circ} \mathrm{C}$ above $80^{\circ} \mathrm{C}$. Negative CTEs have been observed in In previously for the $c$ lattice parameter, but there have been conflicting results. ${ }^{29}$ The values measured here are consistent with the results from Deshpande et al., ${ }^{29}$ who give a CTE of $-8.1 \times 10^{-6} /{ }^{\circ} \mathrm{C}$ at $25^{\circ} \mathrm{C}$, and $-26.9 \times 10^{-6} /{ }^{\circ} \mathrm{C}$ from $27^{\circ} \mathrm{C}$ to $106^{\circ} \mathrm{C}$. Over this same temperature range, we measure $-31.4 \times 10^{-6} /{ }^{\circ} \mathrm{C}$ and clearly confirm contraction of the $c$ lattice parameter on heating. ${ }^{29}$ The $c / a$ ratio for In is plotted in Fig. 14c, showing a decreasing trend from 1.528 to 1.506 as the temperature increases from $12^{\circ} \mathrm{C}$ to $154^{\circ} \mathrm{C}$. Further calculations show that the unit cell volume increases linearly with temperature from $52.79 \AA^{3}$ to $53.51 \AA^{3}$ over this temperature range.

The thermal expansion characteristics of the IMCs that form during the reaction of solders and substrates can also be determined using in situ $\mathrm{x}$-ray diffraction. This provides valuable information about these phases that is relevant to thermal fatigue and mechanical properties of solder joints, and is difficult to obtain otherwise. Figure 15 plots the $d$-spacing versus temperature during cooling for the $\mathrm{Cu}_{6} \mathrm{Sn}_{5}(101)$ peak of the IMC phase that formed during reaction of $\mathrm{Sn}$ with the $\mathrm{Au} / \mathrm{Ni} / \mathrm{Cu}$ surface. The expansion is linear over the temperature range from $200^{\circ} \mathrm{C}$ to $12^{\circ} \mathrm{C}$, with a CTE of $10.1 \times 10^{-6} /{ }^{\circ} \mathrm{C}$. Two other peaks for the $\mathrm{Cu}_{6} \mathrm{Sn}_{5}$ phase were examined, as summarized in Table IV, showing a variation in CTE from $10.1 \times 10^{-6} /{ }^{\circ} \mathrm{C}$ to $18.5 \times 10^{-6} /{ }^{\circ} \mathrm{C}$, with an average value of $13.6 \times 10^{-6} /{ }^{\circ} \mathrm{C}$. One additional peak for an undetermined IMC (peak 5) had a measured CTE of $13.1 \times 10^{-6} /{ }^{\circ} \mathrm{C}$. This range
Table IV. CTE for the Sn/Au-Ni-Cu IMC phases identified in Fig. 7

\begin{tabular}{|c|c|c|c|}
\hline $\begin{array}{l}\text { Diffraction } \\
\text { Peak }\end{array}$ & $\begin{array}{l}\text { Intermetallic } \\
\text { Compound }\end{array}$ & Plane & $\begin{array}{c}\mathrm{CTE} \\
\left(10^{-6} /{ }^{\circ} \mathrm{C}\right), \\
25^{\circ} \mathrm{C} \text { to } 200^{\circ} \mathrm{C}\end{array}$ \\
\hline 1 & $\mathrm{Cu}_{6} \mathrm{Sn}_{5}$ & (101) & 10.1 \\
\hline 2 & $\mathrm{Cu}_{6} \mathrm{Sn}_{5}$ & (002) & 12.2 \\
\hline 5 & Unknown & Unknown & 13.1 \\
\hline 6 & $\mathrm{Cu}_{6} \mathrm{Sn}_{5}$ & (200) & 18.5 \\
\hline
\end{tabular}

of CTE values is similar to those reported elsewhere for intermetallic phases in the Cu-Sn system, ${ }^{17}$ where $\mathrm{Cu}_{6} \mathrm{Sn}_{5}$ and $\mathrm{Cu}_{3} \mathrm{Sn}$ phases were observed.

\section{CONCLUSIONS}

In situ x-ray diffraction using synchrotron radiation was demonstrated to be a useful method for observing phase transformations in low-meltingpoint metals used as base elements for lead-free solder alloys. Microstructural evolution during heating, melting, solidification, and cooling was followed for $\mathrm{Sn}$ and In on different substrates, including in situ measurements of lattice expansion of Sn, In, and the IMC that formed between Sn and a Au-coated copper substrate. Based on the results of the experiments, the following conclusions were made. In situ x-ray diffraction patterns of Sn that was melted and solidified on graphite showed undercoolings up to $56.1^{\circ} \mathrm{C}$ below its equilibrium melting temperature, with an average value of $\Delta T=49.7^{\circ} \mathrm{C}$ for three experiments. These undercoolings were significantly higher than Sn solidified on $\mathrm{Au} / \mathrm{Ni} / \mathrm{Cu}\left(\Delta T=17.3^{\circ} \mathrm{C}\right)$ and on $\mathrm{Cu}\left(\Delta T=10.5^{\circ} \mathrm{C}\right)$ below their respective eutectic temperatures. In contrast, the in situ x-ray diffraction patterns of In that was melted and solidified on graphite showed an average undercooling of $\Delta T=2.8^{\circ} \mathrm{C}$, and similar low values of undercooling for In solidified on $\mathrm{Au}$ and $\mathrm{Cu}$. It is unusually difficult to nucleate solid $\mathrm{Sn}$ from its liquid state, and the reasons for this are not fully understood. Continued work is needed to study the undercooling of Sn and to develop methods to minimize undercooling and provide more refined microstructures with favorable mechanical properties for lead-free solders. Future work is planned to incorporate small amounts of inoculants in attempts to reduce undercooling in Sn, and to follow their effects using in situ x-ray diffraction. In addition to measuring undercooling, in situ x-ray diffraction observations of the lattice parameters of Sn and In were made during heating and cooling. Sn displayed nonlinear expansion in both the $a$ and $c$ directions, and displayed a $c / a$ ratio that increased with temperature. Indium showed linear expansion for the $a$ lattice parameter, and nonlinear contraction, rather than expansion, of the $c$ lattice parameter with increasing temperature, which resulted in a decreasing $c / a$ ratio on heating. The formation of 
intermetallic compounds during reaction of the solder with the substrates was also directly observed, and the results indicated that the principal IMC that forms during solidification of $\mathrm{Sn}$ on $\mathrm{Au} / \mathrm{Ni} / \mathrm{Cu}$ was $\mathrm{Cu}_{6} \mathrm{Sn}_{5}$. This phase has a CTE that varies be-

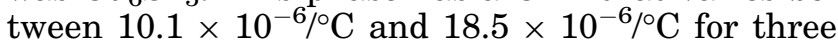
different crystallographic planes examined, and an average value of $13.6 \times 10^{-6} /{ }^{\circ} \mathrm{C}$, which is less than that of $\mathrm{Sn}$ or $\mathrm{Cu}$.

\section{ACKNOWLEDGEMENTS}

The authors would like to thank Mike Santella of Oak Ridge National Laboratory and Suresh Babu of the Ohio State University for assisting with the data analysis, and Jenia Karapetrova of the APS for assisting with the synchrotron beam-line setup and operation. This work was performed under the auspices of the US Department of Energy by Lawrence Livermore National Laboratory under Contract No. DE-AC52-07NA27344, and by Oak Ridge National Laboratory under Contract No. DE-AC0500OR22725. The ORNL portion of this work was fully supported by the Materials Sciences and Engineering Division, Office of Basic Energy Sciences, US Department of Energy. The in situ synchrotron experiments were performed on 34-BM-C at the APS, which is supported by the US DOE, Basic Energy Sciences, Office of Science under Contract No. W-31-109-ENG-38.

\section{OPEN ACCESS}

This article is distributed under the terms of the Creative Commons Attribution Noncommercial License which permits any noncommercial use, distribution, and reproduction in any medium, provided the original author(s) and source are credited.

\section{REFERENCES}

1. K.J. Puttlitz and K.A. Stalter, Handbook of Lead-Free Solder Technology for Microelectronic Assemblies (New York: CRC Press, 2004).

2. D. Swenson, J. Mater. Sci.: Mater. Electron. 18, 39 (2007).

3. J.H. Perepezko, Mater. Sci. Eng. 65, 125 (1984).

4. R. Kinyanjui, L.P. Lehman, L. Zavalij, and E. Cotts, J. Mater. Res. 20, 2914 (2009).

5. Y.-C. Huang, S.-W. Chen, and K.-S. Wu, J. Electron. Mater. 39, 109 (2010).
6. A. LaLonde, D. Emelander, J. Jeannette, C. Larson, W. Rietz, D. Swensen, and D.W. Henderson, J. Electron. Mater. 33,1545 (2004).

7. S.-K. Seo, S.K. Kang, M.G. Ko, D. Dhih, and H.M. Lee, J. Electron. Mater. 38, 2461 (2009).

8. A.U. Telang, T.R. Bieler, J.P. Lucas, K.N. Subramanian, L.P. Lehman, Y. Xing, and E.J. Cotts, J. Electron. Mater. 33, 1412 (2004).

9. L.P. Lehman, S.N. Athavale, T.Z. Fullem, A.C. Giamis, R.K. Kinyanjui, M. Lowenstein, K. Mather, R. Patel, D. Rae, J. Wang, Y. Xing, L. Zavalij, P. Borgesen, and E.J. Cotts, J. Electron. Mater. 33, 1429 (2004).

10. D.W. Henderson, J.J. Woods, T. Goselin, A. Sarkhel, S.K. Kang, W.-K. Choi, D.-.Y. Shih, C. Goldsmith, and K.J. Puttlitz, J. Mater. Res. 9, 1608 (2004).

11. K.N. Subramanian and J.G. Lee, J. Mater. Sci.: Mater. Electron. 15, 235 (2004).

12. T.R. Bieler, H. Jiang, L.P. Lehman, T. Kirkpatrick, and E.J. Cotts, Proceedings of the 56th ECTC (2006), p. 1462.

13. L.P. Lehman, Y. Xing, T.R. Bieler, and E.J. Cotts, Acta Mater. V58, 3546 (2010).

14. I.E. Anderson, J.W. Walleser, J.L. Harringa, F. Labs, and A. Kracher, J. Electron. Mater. 38, 2770 (2009).

15. T. Massalski, H. Okamoto, P.R. Subramanian, and L. Kacprzak, Binary Alloy Phase Diagrams, 2nd ed., Vol. 2 (Materials Park, Ohio: ASM International, 1990).

16. P. Villars, Pearson's Handbook of Crystallographic Data for Intermetallic Phases, desk ed., Vol. 2 (Materials Park, Ohio: ASM International, 1997).

17. K.-J. Wang, Y.-C. Lin, J.-G. Duha, C.-Y. Cheng, and J.-J. Lee, J. Mater. Res. 25, 972 (2010).

18. G.J. Jackson, H. Lu, R. Durairaj, N. Hoo, C. Bailey, N.N. Ekere, and J. Wright, J. Electron. Mater. 33, 1524 (2004).

19. MUCAL program (http://www.csrri.iit.edu/mucal.html) based on data from: W.H. McMaster, N.K. Del Grande, J.H. Mallett, and J.H. Hubbell, Lawrence Livermore National Laboratory Report UCRL-50174 (section I 1970, section II 1969, section III 1969 and section IV, 1969).

20. J.W. Elmer, T.A. Palmer, and E.D. Specht, Metall. Mater. Trans. A 38A, 464 (2007).

21. J.W. Elmer, T.A. Palmer, S.S. Babu, and E.D. Specht, Mater. Sci. Eng. A V391, 104 (2005).

22. J.W. Elmer, T.A. Palmer, S.S. Babu, and E.D. Specht, Scripta Mater. 52, 1051 (2005).

23. J.W. Elmer, T.A. Palmer, and E.D. Specht, J. Vac. Sci. Technol. A 24, 978 (2006).

24. J.W. Elmer, E.D. Specht, and M. Kumar, J. Electron. Mater. 39,273 (2010).

25. P. Hammersley, S.O. Svensson, M. Hanfland, A.N. Fitch, and D. Häusermann, High Press. Res. 14, 235 (1996).

26. Gangulee, G.C. Das, and M.B. Bever, Metall. Trans. 4, 2063 (1973).

27. J.P. Jan, W.B. Pearson, A. Kjekshus, and S.B. Woods, Can. J. Phys. 41, 2252 (1963).

28. V.T. Deshpande and D.B. Sirdeshmuk, Acta Cryst. 15, 294 (1962).

29. V.T. Deshpande and R.R. Pawar, Acta Cryst. 25, 415 (1969). 